\title{
Notes on African Crowned Eagle Stephanoaetus coronatus diet in savanna and forest in KwaZulu-Natal, South Africa
}

\author{
Craig T. Symes $^{1 \star}$ and Annie R. Antonites ${ }^{2,3}$ \\ ${ }^{1}$ School of Animal, Plant and Environmental Sciences, University of the Witwatersrand, \\ Private Bag 3, Wits 2050, South Africa. \\ ${ }^{2}$ Anthropology Department, Yale University, 10 Sachem Street, New Haven, Connecticut \\ 06520, USA. \\ ${ }^{3}$ Department of Anthropology and Archaeology, University of Pretoria, Pretoria 0002, South \\ Africa
}

*Corresponding author, e-mail: craig.symes@wits.ac.za

Our study reports on contrasts in prey items from African Crowned Eagle (Stephanoaetus coronatus) nesting in forest $(n=1)$ and savanna $(n=2)$ biomes in KwaZulu-Natal, South Africa. At least 12 taxa were identified at a forest nest, of which $92.1 \%$ were neonate/juvenile. Bovids and procaviids represented $73.7 \%$ and $19.6 \%$ of the diet respectively whilst Samango Monkey (Cercopithecus albogularis), a common forest species, represented only $1.7 \%$ of prey items. Other species made up $5.0 \%$ and included a range of species not found in the forest (e.g. Ourebia ourebi, Lepus sp., Ovis capra). At the savanna nests at least four taxa were identified, of which $\mathbf{7 3 . 1 \%}$ of prey items were adult. The majority of prey items were identified as procaviids $(87.0 \%)$ with $5.6 \%$ and $7.4 \%$ of prey items represented by $C$. albogularis/pygerythrus and other remains (e.g. Capra hircus, Philantomba monticola) respectively. In South Africa, where total forest area is reduced compared to regions further north, the dietary range of African Crowned Eagles may include a wider diversity of prey from different biomes; feeding generalisation and opportunism may therefore be an important strategy for the maintenance of African Crowned Eagles populations in the region.

Keywords: Crowned Eagle, hyrax, prey diversity, primate, oribi 
The African Crowned Eagle (Stephanoaetus coronatus) is the only eagle confined to forest in sub-Saharan Africa (Brown et al. 1982, Boshoff 1997). Dietary composition is reported for a number of sites (e.g. Jarvis et al. 1980, Struhsaker and Leakey 1990, Boshoff et al. 1994, Schultz 2002, McGraw et al. 2006, Skorupa 2008) and includes ungulates of up to $30 \mathrm{~kg}$ (Brown 1971, Daneel 1979, Brown 1982, Steyn 1982). Because of its widespread distribution, where prey species diversity and abundance may differ markedly, proportions of prey items may differ significantly between regions. In South Africa, African Crowned Eagles are confined to naturally fragmented forest patches, although they utilize exotic trees (e.g. Eucalyptus spp.) and heavily wooded savanna for nesting (Boshoff 1997, Malan and Shultz 2002, Malan 2005). The inclusion of prey from surrounding habitats (e.g. grassland) is therefore not unexpected, and has been documented in numerous studies (see Jarvis et al. 1980, Boshoff 1997). In fact, with its extension into the grassland biome because of commercial plantations and woody vegetation encroachment, the species is quite likely to include a wider variety of non-forest prey items, than populations further north in tropical Africa where natural forest and woodland are more extensive.

Our study reports on the diet of African Crowned Eagle, determined from bones collected from a single active nest in an afromontane forest and two inactive nests in savanna in KwaZulu-Natal, South Africa. We investigate prey species and age composition and discuss the findings in relation to habitat type and studies of African Crowned Eagle diets elsewhere in Africa.

Bones of prey remains were collected from beneath an African Crowned Eagle nest in a large emergent Outeniqua Yellowwood Podocarpus falcatus snag ( $\mathrm{ht}=$ c. 15 m) deep in Ngele forest (30³1'30"S 29०40'08"E, c. 690 ha) at opportunistic intervals during late-1995 to early-1996. The afromontane forest is surrounded by a natural mosaic of grassland and forest patches and commercial afforestation (i.e. Pinus sp. and Eucalyptus sp.). During each collection period (three periods of approximately $1 \mathrm{~h}$ each) the gap below the nest (c. $10 \mathrm{~m}$ radius from tree trunk), created by the senescing tree was searched extensively for prey remains. The nest was discovered in c. 1993 and destroyed when the tree fell over in c. June 1997. Prey remains were also collected (in a final visit to the site) from the nest structure that landed on the forest floor when it was destroyed. 
During early-1996 two inactive African Crowned Eagle nest sites (estimated

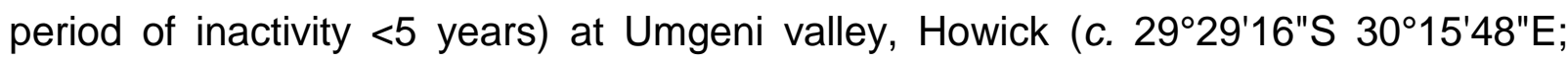
savanna site), both in live trees within $1 \mathrm{~km}$ of each other, and within $100 \mathrm{~m}$ of the river at the base of the valley, were visited. Both nests were situated in well wooded savanna dominated by Acacia spp. Nests were identified as African Crowned Eagle by regular visitors to the valley, although it is unclear whether they were used by separate pairs (D. Hoddinott pers. comm. 1995, who regularly visited the site and documented the use of the nests by African Crowned Eagles). All bones beneath each nest, within a c. $10 \mathrm{~m}$ radius of the tree main stem were collected. Searching at each nest occurred for approximately $2 \mathrm{~h}$ during a single visit. All bones were identified by ARA using reference collections at the Department of Mammalogy of the Ditsong National Museum of Natural History (formerly the Transvaal Museum), Pretoria.

The presence of a selective array of species highlights the importance of studies like this in identifying and documenting prey items of African Crowned Eagle. At least 12 and four prey species were identified for Ngele forest and Umgeni valley respectively. These include a variety of species representing a wide range of age classes (Table 1). At Ngele forest, bovid (family Bovidae) remains represented $73.7 \%$ of the diet whilst procaviids represented $19.6 \%$ of prey remains. Samango Monkey (Cercopithecus albogularis), a species common to the forest, represented $1.7 \%$ whilst other species made up $5.0 \%$ (Table 1). At the forest site, where prey species were generally larger (i.e. bovids), more neonates/juveniles (92.1\%) were recorded (Table 1). At Umgeni valley (savanna site) the majority of prey items were identified as procaviid (family Procaviidae) (87.0\%), with $5.6 \%$ and $7.4 \%$ of Samango/Vervet Monkey and other remains respectively. Bovid remains were conspicuously absent (Table 1). At the savanna site, where a greater proportion of prey items were of smaller size (i.e. procaviids) there was a larger proportion (73.1\%) of adults (Table 1 ).

African Crowned Eagle has a widespread distribution in Africa and prey items are likely to differ between regions. In our study the low number of primate remains at the forest site $(1.8 \%)$, where Samango Monkeys are common (and Vervet Monkey absent), contrasts to the diet of African Crowned Eagle in East and West Africa (e.g. Mitani et al. 2001, Shultz 2002, Sanders et al. 2003, McGraw et al. 2006, Skorupa 2008). This may reflect the overall availability of prey to African Crowned Eagles at the site, however, Samango Monkeys are vocal and may appear more common than many other species (i.e. bovids). Therefore, until prey densities at both sites are 
known, we are unable to infer whether preferences for any specific prey type are significant. In a South African study cercopithecids made up a slightly higher proportion (8\%) of the diet in both biomes, suggesting there may be unique differences in prey proportions between individual nesting sites and pairs (Boshoff et al. 1994). In forests, African Crowned Eagle may specialize in feeding on monkeys, particularly when diversity is high (Mitani et al. 2001, Shultz 2002). However, large proportions of primate prey may reflect abundance of natural primate populations rather than preference (Sanders et al. 2003). In two studies at Taï Park, Ivory Coast, where eight cercopithecid monkey and at least two prosimian species were present, $49 \%$ (Shultz 2002) and $56 \%$ of prey items were primates (McGraw et al. 2006). In other studies, primates represented much higher proportions of African Crowned Eagle diets; $81 \%$ at Ngogo in Kibale National Park (Sanders et al. 2003), 84\% in Kibale Forest (Struhsaker and Leakey 1990) and $88 \%$ in the Kanyawara area of Kibale (Skorupa 2008). In some cases temporal changes may occur in response to prey abundance (as a result of humans), such as in the Matumbi Hills of Tanzania where Blue (Samango) Monkey dietary contributions decreased from c. $80 \%$ to $20 \%$ with an increased clearing of farmlands in the vicinity of nest sites (Msuya 1993). However, despite our limited sample size, our study suggests that African Crowned Eagles are not prey specialists for primates and in southern Africa have diversified their diet (Boshoff et al. 1994).

Interpretations of diets for species are often speculative and greatly influenced by sample size. Although our data are from a limited number of nests (cf. Boshoff et al. $1994 ; n=34$ ), we stress their value in contributing to a greater understanding of African Crowned Eagle diets throughout their range. In the savanna biome, the dietary proportions in our study varied from those identified by Boshoff et al. (1994) with the majority of prey items constituting procaviids (87.0\%) and, to a lesser extent, Samango/Vervet Monkey (5.6\%) and other remains (7.4\%). However, our results may be influenced by the selective removal of prey items beneath the nest by scavengers. Also, smaller species may be under-represented in the samples because small bones may be less detectable during sampling, become entangled in nest material, deteriorate more rapidly in a forest environment or are consumed whole by eagles (Msuya 1993; Chittenden and Myburgh1994).

At the savanna site (Umgeni Valley NR) more time may have passed since the last nesting episode, resulting in greater removal of prey remains from beneath the 
nests. However, the high proportion of procaviid samples may be associated with a period of high procaviid abundance in the region (CTS pers. obs.). Bovid remains were conspicuously absent from Umgeni valley despite nests being located in a reserve (Umgeni Valley NR) where such prey is abundant (CTS pers. obs.). At the forest site (Ngele), bovid remains represented a larger proportion of the diet $(73.7 \%)$ whilst procaviids represented less (19.6\%). Whether such dietary proportions represent specialist preferences or reflect prey abundance remains to be investigated. The Ngele nest was situated in a large afromontane forest with prey dominated by small to medium sized bovids, although some prey items may possibly have exceeded $25 \mathrm{~kg}$. These large prey items may truly represent the diet of African Crowned Eagles in the region, although it is not unreasonable to assume that some may have been sourced from illegal snaring methods in the forest (Brown et al. 1982, Msuya 1993). This requires further investigation, and considering the frequency of snares found in the forest (CTS pers. obs.), needs to be recognized as a potential source of eagle prey. The Ngele forest nest bordered communal farmlands and it is not surprising that domestic livestock was recorded as part of the prey. African Crowned Eagles have been accused of stock theft and persecuted by shooting and trapping (Boshoff and Vernon 1980, Jarvis et al. 1980). Unfortunately, we were not able to monitor the responses of local residents in the study area but suspect that they are aware of African Crowned Eagle predating domestic livestock. In suburban environments, African Crowned Eagles are known to feed on domestic cats and dogs (Boshoff 1990, Chittenden and Myburgh1994, Ken Gordon pers. comm.) and in some urban areas they may be perceived as pests. Despite being considered a true forest species, African Crowned Eagles are known to prey on a variety of animals (Oatley 1989). It is not unexpected that they prey on species outside the naturally fragmented mistbelt mixed Podocarpus forest of south-eastern South Africa. This may be particularly so during fluctuations in forest resources. To maximize hunting efficiency African Crowned Eagles may thus incorporate a diversity of prey into the diet and may include atypical prey items such as fish (Sharp 2002). The ability of African Crowned Eagles to efficiently utilize abundant and available prey in quite different environments may thus ensure their persistence in the region.

Acknowledgements - The Department of Water Affairs and Forestry (Weza) provided access to the nest site and Craig Breedt organised accommodation at Mackton Lodge during field 
trips to Ngele forest. Ditsong National Museum of Natural History provided facilities for bone identification. ARA wishes to thank Ina Plug for assistance with some of the identifications.

\section{References}

Boshoff AF. 1990. On hungry eagles and domestic pets. Birding South Africa 42: 3.

Boshoff AF. 1997. Crowned eagle Stephanoaetus coronatus. pp 194-195. In: Harrison JA, Allan DG, Underhill LG, Herremans M, Tree AJ, Parker V, Brown CJ (eds). The Atlas of Southern African birds Vol 1: Non-passerines. BirdLife South Africa, Johannesburg.

Boshoff AF, Palmer NG, Vernon CJ, Avery G. 1994. Comparison of the diet of crowned eagles in the savanna and forest biomes of south-eastern South Africa. South African Journal of Wildlife Research 24(1-2): 26-31.

Boshoff AF, Vernon CJ. 1980. The distribution and status of some eagles in the Cape Province. Annals of the Cape Provincial Museums (Natural History) 13: 107-132.

Brown LH. 1971. The relations of the crowned eagle Stephanoaetus coronatus and some of its prey animals. Ibis 113(2): 240-243.

Brown LH. 1982. The prey of the crowned eagle Stephanoaetus coronatus in Central Kenya. Scopus 6: 91-94.

Brown LH, Urban EK, Newman K. 1982. The birds of Africa, Vol. 1. Academic Press. London. Chittenden H, Myburgh N. 1994. Observations at a Crowned Eagle nest. Birding in Southern Africa 46(4): 112-114.

Daneel ABC. 1979. Prey size and hunting methods of the crowned eagle. Ostrich 50: 120121.

Groenewald A, Groenewald L, Hartley R. 2002. Moult and hunting behaviour of a captive crowned eagle from juvenile to post-adult over 13 years. Honeyguide 48: 234-237.

Jarvis MJF, Currie MH, Palmer NG. 1980. Food of crowned eagles in the Cape Province, South Africa. Ostrich 51: 215-218.

Malan G. 2005. Reproductive success and nesting periodicity of a pair of African Crowned Eagles breeding in KwaZulu-Natal. Ostrich 76(3\&4): 215-218.

Malan G, Shultz S. 2002. Nest-site selection of the Crowned Hawk-eagle in the forests of KwaZulu-Natal, South Africa, and Taï, Ivory Coast. Journal of Raptor Research 36: 300308.

McGraw WS, Cooke C, Shultz S. 2006. Primate remains from African crowned eagle (Stephanoaetus coronatus) nests in Ivory Coast's Tai Forest: Implications for primate predation and early hominid taphonomy in South Africa. American Journal of Physical Anthropology 131: 151-165. 
Mitani JC, Sanders WJ, Lwanga JS, Windfelder TL. 2001. Predatory behavior of crowned hawk-eagles (Stephanoaetus coronatus) in Kibale National Park, Uganda. Behavioral Ecology and Sociobiology 49(2-3): 187-195.

Msuya CA. 1993. Feeding habits of Crowned Eagle Stephanoaetus coronatus in Kiwengoma Forest Reserve, Matumbi Hills, Tanzania. In: Proceedings of the $8^{\text {th }}$ Pan-African Ornithological Congress, (ed) R.T. Wilson, Vol. 268:118-120. Annales Sciences Zoologiques, Musee Royal de L'Afrique Central Tervuren, Belgique,

Oatley TB. 1989. Biogeography of the forest avifauna in South Africa. pp. 48-59. In: Geldenhuys CJ (ed). Biogeography of the mixed evergreen forests of southern Africa. Occassional Report No. 45. Foundation for Research and Development. Pretoria.

Sanders WJ, Trapani J, Mitani JC. 2003. Taphonomic aspects of crowned hawk-eagle predation on monkeys. Journal of Human Evolution 44: 87-105.

Sharp C. 2002. Crowned eagle fishing? Honeyguide 48: 253.

Shultz S. 2002. Population density, breeding chronology and diet of crowned eagles Stephanoaetus coronatus in Taï National Park, Ivory Coast. Ibis 144(1): 135-138.

Skorupa JP. 2008. Crowned eagles Strephanoaetus coronatus in rainforest: observations on breeding chronology and diet at a nest in Uganda. Ibis 131(2): 294-298.

Steyn P. 1982. Birds of prey of southern Africa. David Philip, Cape Town.

Struhsaker TT, Leakey M. 1990. Prey selectivity by crowned hawk-eagles on monkeys in the Kibale Forest, Uganda. Behavioral Ecology and Sociobiology 26(6): 435-443.

Tarboton WR, Allan DG. 1984. The status and conservation of birds of prey in the Transvaal. Transvaal Museum Monograph 3. Pretoria. 
Table 1: Prey species of African Crowned Eagle as determined from bones collected at Ngele forest (forest site) and Umgeni valley (savanna site). $\mathrm{NISP}=$ Number of Identified Specimens; $\mathrm{a} / \mathrm{j} / \mathrm{n} / \mathrm{u}=$ adult/juvenile/neonate/unknown (given for NISP).

\begin{tabular}{|c|c|c|c|c|c|c|c|c|c|c|c|c|}
\hline \multirow{3}{*}{ Species } & \multicolumn{6}{|c|}{ Ngele forest } & \multicolumn{6}{|c|}{ Umgeni valley } \\
\hline & \multicolumn{2}{|c|}{$\operatorname{NISP}(n=179)$} & \multicolumn{3}{|c|}{ Skeletal part } & \multirow{2}{*}{$\begin{array}{c}\text { Age } \\
a / j / n / u\end{array}$} & \multicolumn{2}{|c|}{ NISP $(n=54)$} & \multicolumn{3}{|c|}{ Skeletal part } & \multirow{2}{*}{$\begin{array}{c}\text { Age } \\
a / j / n / u\end{array}$} \\
\hline & Positive & Probable & Cranial & Body & Limbs & & Positive & Probable & Cranial & Body & Limbs & \\
\hline Samango monkey (Cercopithecus albogularis) & 3 & 0 & 1 & 0 & 2 & $2 a / 1 j$ & 0 & 2 & 2 & 0 & 0 & $2 a$ \\
\hline Samango/vervet monkey & - & - & - & - & - & - & 1 & 0 & 1 & 0 & 0 & $1 \mathrm{a}$ \\
\hline Marsh mongoose (Atilax paludinosus) & 1 & 0 & 1 & 0 & 0 & $1 \mathrm{j}$ & - & - & - & - & - & - \\
\hline Indeterminate mongoose & 3 & 0 & 0 & 1 & 2 & $2 \mathrm{j} / 1 \mathrm{u}$ & - & - & - & - & - & - \\
\hline Tree hyrax (Dendrohyrax arboreus) & 9 & 0 & 8 & 0 & 1 & $1 \mathrm{a} / 6 \mathrm{j} / 2 \mathrm{u}$ & - & - & - & - & - & - \\
\hline Rock hyrax (Procavia capensis) & 3 & 1 & 3 & 1 & 0 & $2 a / 1 j / 1 u$ & 32 & 7 & 38 & 0 & 1 & $29 a / 8 j / 2 u$ \\
\hline Indeterminate hyrax & 22 & 0 & 0 & 18 & 4 & $2 \mathrm{a} / 2 \mathrm{j} / 18 \mathrm{u}$ & 8 & 0 & 2 & 4 & 2 & $6 a / 2 j$ \\
\hline Sheep (Ovis capra) & 1 & 0 & 0 & 0 & 1 & $1 \mathrm{j}$ & - & - & - & - & - & - \\
\hline Goat (Capra hircus) & - & - & - & - & - & - & 1 & 0 & 1 & 0 & 0 & $1 \mathrm{j}$ \\
\hline Sheep/Goat (Ovis/Capra) & - & - & - & - & - & - & 1 & 1 & 1 & 0 & 1 & $1 \mathrm{j} / 1 \mathrm{n}$ \\
\hline Redunca sp. & 0 & 3 & 0 & 0 & 3 & 3j & - & - & - & - & - & - \\
\hline Bushbuck (Tragelaphus scriptus) & 1 & 6 & 0 & 0 & 7 & $1 \mathrm{a} / 6 \mathrm{j}$ & - & - & - & - & - & - \\
\hline Oribi (Ourebia ourebi) & 1 & 0 & 1 & 0 & 0 & $1 \mathrm{j}$ & - & - & - & - & - & - \\
\hline Common duiker (Sylvicapra grimmia) & 3 & 2 & 3 & 0 & 2 & $5 j$ & - & - & - & - & - & - \\
\hline Blue duiker (Philantomba monticola) & 3 & 0 & 1 & 1 & 1 & $1 \mathrm{a} / 1 \mathrm{j} / 1 \mathrm{u}$ & 0 & 1 & 1 & 0 & 0 & $1 \mathrm{j}$ \\
\hline Indeterminate bovid (small) & 12 & 0 & 5 & 7 & 0 & $10 \mathrm{j} / 2 \mathrm{u}$ & - & - & - & - & - & - \\
\hline Indeterminate bovid (small to medium) & 6 & 0 & 1 & 0 & 5 & $5 \mathrm{j} / 1 \mathrm{n}$ & - & - & - & - & - & - \\
\hline Indeterminate bovid (Redunca size) & 25 & 0 & 0 & 3 & 22 & $1 \mathrm{a} / 24 \mathrm{j}$ & - & - & - & - & - & - \\
\hline Indeterminate bovid (>Redunca size) & 2 & 0 & 0 & 0 & 2 & $2 \mathrm{j}$ & - & - & - & - & - & - \\
\hline Indeterminate bovid (medium) & 68 & 0 & 1 & 18 & 49 & $66 \mathrm{j} / 2 \mathrm{n}$ & - & - & - & - & - & - \\
\hline Lepus sp. & 1 & 0 & 0 & 1 & 0 & $1 \mathrm{u}$ & - & - & - & - & - & - \\
\hline Indeterminate ibis * & 1 & 0 & 0 & 0 & 1 & $1 \mathrm{a}$ & - & - & - & - & - & - \\
\hline Indeterminate raptor (large) & 1 & 0 & 0 & 0 & 1 & $1 \mathrm{a}$ & - & - & - & - & - & - \\
\hline \multirow[t]{2}{*}{ Indeterminate bird (chicken/guineafowl size) } & 1 & 0 & 0 & 1 & 0 & $1 \mathrm{u}$ & - & - & - & - & - & - \\
\hline & 167 & 12 & 25 & 51 & 103 & $12 / 137 / 3 / 27$ & 43 & 11 & 46 & 4 & 4 & $38 / 13 / 1 / 2$ \\
\hline
\end{tabular}

* possibly Hadeda Ibis Bostrychia hagedash that sometimes forages on forest floor. 